\title{
Faktor-Faktor yang Berhubungan dengan Kelaikan Kantin Sehat di Sekolah Dasar Kecamatan Medan Belawan
}

\author{
Rismawati \\ Program Pascasarjana Universitas Sari Mutiara Indonesia \\ Jl. Kapten Muslim No 79, Medan 20123 \\ E-Mail : risma_rys@yahoo.com
}

\begin{abstract}
Abstrak
Program kantin sehat sekolah yang mulai diadakan pada tahun 2009 oleh Kemendiknas merupakan salah satu intervensi untuk menjaga keamanan pangan terutama pada sekolah-sekolah di Indonesia. Berdasarkan survei awal yang dilakukan 44 kantin di sekolah dasar Kecamatan Medan Belawan, sebanyak 80\% kantin sekolah belum memenuhi syarat kesehatan. Tujuan penelitian ini adalah untuk mengetahui faktor-faktor yang berhubungan dengan kelaikan kantin sehat di sekolah dasar kecamatan Medan Belawan tahun 2017. Jenis penelitian ini adalah penelitian analitik dengan desain cross sectional. Populasi dari penelitian ini adalah 44 kantin di sekolah-sekolah dasar di kecamatan Medan Belawan, dengan teknik pengampilan sampel dengan total populasi. Hasil penelitian diperoleh terdapat hubungan pengetahuan pengelola kantin $(P v=0,014)$, sikap pengelola kantin $(p v=0,003)$, omset bulanan kantin $(p v=0,010)$, pengawasan internal $(p v=0,10)$ dan pengawasan eksternal $(p v=0,002)$ dengan kelaikan kantin sehat. Adapun faktor pengetahuan pengelola kantin merupakan faktor dominan yang mempengaruhi kelaikan kantin sehat. Sehingga dengan demikian perlu kiranya diberikan pelatihan kepada pengelola kantin di bidang higiene dan sanitasi makanan baik yang diselenggakan oleh pihak sekolah maupun instansi kesehatan terkait di wilayah Kecamatan Medan Belawan, agar pengelola kantin dapat mengelola kantinnya dengan baik sesuai dengan persyaratan higiene sanitasi kantin sehat di sekolah. Selain itu juga agar diupayakan pengawasan baik oleh pihak puskesmas maupun pihak sekolah kepada kantin sekolah mengenai higiene sanitasi sekolah.
\end{abstract}

Kata kunci : Kantin Sehat, Sekolah Dasar, Determinan

\begin{abstract}
The healthy school canteen program started in 2009 by the Ministry of National Education is one of the interventions to maintain food security especially in schools in Indonesia. Based on a preliminary survey conducted by 44 canteens in elementary school of Medan Belawan sub-district, $80 \%$ of school canteen. The purpose of this study is to determine the factors associated with the healthy canteen fairness in the elementary school district Belawan in 2017. This type of research is analytical research with cross sectional design. The population of this research is 44 canteen in elementary school in subdistrict of Medan Belawan, with sample appraisal technique with total population. The result of the research showed that there was a correlation between knowledge of canteen management $(P v=0,0 / 4)$, canteen manager attitude $(p=0,003)$, monthly canteen turnover $(p v=0,010)$, internal control $(p v=0,10)$ and external supervision $(p v=0,002)$ with healthy cafeteria eligibility. The knowledge factor of canteen management is the dominant factor affecting the healthy cafeteria's goodness. Therefore, it is necessary to provide training to canteen managers in the field of hygiene and food sanitation either held by the school and related health agencies in the District of Medan Belawan, so canteen managers can manage the canteen properly in accordance with the requirements of healthy sanitation hygiene in school canteen. In addition to the effort to control both the puskesmas and the school to the school cafeteria on the hygiene of school sanitation.
\end{abstract}

Keywords : LBW, Gestational Age, Distance Pregnancy, Parity, Obstetric History 


\section{Pendahuluan}

Anak-anak sekolah terutama anak usia sekolah dasar sangat menyukai pangan jajanan. Sehingga para pedagang berupaya untuk memberikan penampilan yang menarik dan rasa yang disenangi anakanak dengan menambahkan bahan-bahan tertentu tanpa memperdulikan keamanannya. Menurut data Food and Agriculture Organization (FAO, 2013), diperoleh data bahwa anak usia 6 sampai 11 tahun merupakan konsumen tersering dan terbesar dalam mengkonsumsi makanan jajanan. Kebiasaan mengkonsumsi makanan jajanan mengalami peningkatan yaitu $74 \%$ menjadi $95 \%$ dari tahun 2012 sampai 2013.

Data Profil Jajanan Anak Sekolah (PJAS) berdasarkan pengawasan rutin yang dilakukan BPOM mengemukakan bahwa dalam 5 tahun terakhir (2006 2010) menunjukkan, hampir setengah jajanan anak disekolah tidak memenuhi persyaratan keamanan pangan. Peraturan pemerintah No. 28 tahun 2004 tentang keamanan, mutu, dan gizi pangan, memberikan wewenang kepada Badan POM untuk melakukan pengawasan keamanan, mutu dan gizi pangan yang beredar. Salah satu prioritas pangan yang menjadi perhatian khusus Badan POM RI adalah pangan jajanan anak sekolah (PJAS). ${ }^{2}$

Menurut data World Health Organisation tahun 2003 menyatakan bahwa di negara maju seperti America 3000 orang meninggal setiap tahunnya akibat foodborn desease. Menurut data Center for Science in Public Interest (2012), di Asia khususnya negara maju seperti Cina, diperoleh bahwa lebih dari 250 anak sakit dan 40 orang anak meninggal pertahun akibat terkontaminasi makanan jajanan yang tidak sehat. ${ }^{3}$

Data di Indonesia menurut hasil survei Badan Pengawas Obat dan Makanan Republik Indonesia, mendapatkan data bahwa $85 \%$ anak sekolah mengkonsumsi makanan jajanan di lingkungan sekolah baik dari penjaja maupun di sekitar kantin sekolah. Frekuensi makanan ringan lebih dari 11 kali perminggu $(66 \%){ }^{2}$

Berdasarkan data BPOM pada tahun 2010 makanan jajanan masih menyebabkan keracunan pangan. Data KLB keracunan pangan yang dihimpun oleh Direktorat Surveilan dan Penyuluhan Keamanan Pangan (SPKP) Badan POM dari 26 Balai POM di seluruh Indonesia pada tahun 2006 menunjukkan (21.4\%) kasus terjadi di lingkungan sekolah dan (75.5\%) kelompok siswa anak sekolah dasar (SD) paling sering mengalami keracunan Pangan Jajanan Anak Sekolah (PJAS). ${ }^{2}$

Hasil pengawasan pangan jajanan anak sekolah tahun 2005 yang dilakukan oleh 18 balai besar/ Balai BOM dengan cakupan pengambilan sampel makanan jajanan anak sekolah seluruhnya 861 sampel yang diperiksa/diuji, yang memenuhi syarat sebanyak 517 sampel $(60.04 \%)$, dan yang tidak memenuhi syarat sebanyak 344 sampel (39.96\%). Sedangkan pada tahun 2006 hasil pengawasan PJAS oleh Badan POM menunjukan bahwa dari 2.903 sampel yang diambil dari 478 SD di 26 ibukota propinsi di Indonesia sebesar 50.6\% sampel yang memenuhi syarat (MS) dan $49.4 \%$ tidak memenuhi syarat (TMS). ${ }^{2}$

Kurangnya praktek keamanan pangan penjaja PJAS di lingkungan sekolah, dikarenakan kurang perhatian pihak sekolah dan kemungkinan masih kurangnya akses informasi mengenai gizi dan keamanan pangan. Wilayah sekolah serta mutu sekolah juga sangat menentukan kualitas penjaja PJAS di lingkungan sekolah. Hasil monitoring dan verifikasi profil keamanan pangan jajanan anak sekolah (PJAS) nasional tahun 2008 menunjukkan bahwa pengetahuan gizi dan keamanan penjaja PJAS di luar jawa lebih baik dibandingkan di Jawa, serta pengetahuan gizi dan keamanan pangan penjaja PJAS di sekolah dengan status akreditasi A lebih baik daripada Akreditasi B. Mengingat pentingnya peranan kantin 
yang memenuhi kaidah-kaidah keamanan pangan serta pentingnya pangan jajanan yang sehat bagi anak sekolah dan masih banyaknya sekolah terutama SD yang belum memiliki kantin yang memenuhi standart kantin sehat, dan adanya perbedaan kantin berdasarkan mutu sekolah, maka peneliti menganggap perlu untuk melakukan analisis faktor kesiapan sekolah dalam mengelola kantin sehat di sekolah dasar.

Program kantin sehat sekolah yang mulai diadakan pada tahun 2009 oleh Kemendiknas merupakan salah satu intervensi untuk menjaga keamanan pangan terutama pada sekolah-sekolah di Indonesia. Pada tahun 2009 program kantin sehat dilaksanakan pada 288 sekolah pada 7 propinsi, dan pada tahun 2010 program kantin sehat dikembangkan pada setiap propinsi di Indonesia serta dijalinnya kerjasama antara Kemendiknas dengan BPOM. Hal ini berlaku sejak dikeluarkannya Permendiknas No. 57 Tahun 2009 mengenai pemberian dana hibah untuk pengembangan sekolah sehat dan salah satu jenis bantuan pembangannya adalah melalui penataan sarana prasarana kantin sekolah, dimana Kemendiknas dan BPOM memberikan bimbingan kepada guru dan pengelola kantin mengenai makanan yang sehat dan bergizi, serta memberi bantuan dana sebesar 30 juta rupiah untuk memperbaiki kantin agar memenuhi syarat kantin sehat. ${ }^{5}$ Berdasarkan survei awal yang dilakukan 44 kantin di sekolah dasar Kecamatan Medan Belawan, sebanyak $80 \%$ kantin sekolah belum memenuhi syarat kesehatan, dimana keadaan kantinnya sangat memprihatinkan, bangunan kantin yang tidak layak, penjamah makanan (pengelola kantin) tidak memperhatikan kebersihan tempat pengolahan makanannya, tempat penyajian makanan yang tidak bersih dan makanan yang disajikan dalam keadaan terbuka (tidak ditutup), banyak sampah berserakan, juga terdapat lalat yang berterbangan sehingga dikhawatirkan lalat bisa singgah ke makanan yang disajikan.
Kondisi tersebut tentunya mempengaruhi higiene sanitasi kantin sekolah tersebut. Sedangkan faktor-faktor yang berhubungan dengan kelaikan kantin sehat berkaitan erat dengan higiene sanitasi disekitar lingkungannya.

Pengelola kantin mempunyai

peranan penting dalam pengolahan makanan yang sangat mempengaruhi keadaan higiene sanitasi, faktor sumber daya manusia diantaranya adalah pendidikan yang mengarah pada pengetahuan tentang kebersihan diri sendiri dan lingkungan. Tingkat pendidikan pengelola kantin akan mempengaruhi wawasan atau pengetahuannya, pengelola kantin yang berpendidikan lebih tinggi akan mempunyai pengetahuan yang lebih luas dibandingkan dengan seseorang yang tingkat pendidikannya lebih rendah. Pengelola kantin yang memiliki tingkat pendidikan yang rendah akan mempengaruhi pengetahuannya tentang higiene sanitasi pengolahan makanan yang dapat mempengaruhi kualitas makanan yang disajikan kepada konsumen.

Disamping itu, pengelola kantin harus memiliki sikap yang baik dalam higiene sanitasi dalam pengolahan makanan seperti tidak merokok pada saat bekerja, selalu mencuci tangan selama bekerja, setelah bekerja, dan setelah keluar dari toilet, selalu memakai pakaian kerja yang benar dan bersih, menutup mulut saat batuk dan bersin dan tidak menyisir rambut di dekat makanan.

Selain itu, omset bulanan juga mempengaruhi kondisi penerapan higiene sanitasi di dalam kantin, karena jika kantin ramai dikunjungi siswa, bisa jadi higiene sanitasi semakin berkurang, dimana siswa akan membuang sampah sisa makannya ke sembarang tempat sehingga mempengaruhi kenyamanan dan kebersihan lingkungan di sekitar kantin. Demikian juga halnya dengan pengaruh pengawasan internal yang dilakukan oleh pihak sekolah maupun pengawasan eksternal yang dilakukan oleh Puskesmas Medan Belawan untuk 
melakukan monitoring kantin sehat di sekolah-sekolah dasar kawasan Kecamatan Medan Belawan, melalui intervensi dan kegiatan bimbingan kepada guru dan pengelola kantin mengenai makanan yang sehat dan bergizi, akan dapat menciptakan kelaikan kantin sehat di sekolah-sekolah dasar di Kecamatan Medan Belawan.

\section{Metode Penelitian}

Jenis penelitian ini merupakan penelitian analitik dengan desain cross sectional yang bertujuan untuk mengetahui faktor-faktor yang berhubungan dengankelaikan kantin sehat di sekolah-sekolah dasar kecamatan Medan Belawan. Populasi dari penelitian ini adalah 44 kantin di sekolah-sekolah dasar di kecamatan Medan Belawan. Sedangkan jumlah sampel dalam penelitian ini adalah seluruh populasi (total populasi) yang berjumlah 44 kantin sekolah dasar di Kecamatan Medan Belawan.

\section{Hasil Penelitian}

\section{Analisa Univariat}

Tabel 1. Karakteristik Responden

\begin{tabular}{llcc}
\hline Variabel & Kategori & n & \% \\
\hline Umur & $<40$ tahun & 24 & 54,5 \\
& $\geq 40$ tahun & 20 & 45,5 \\
Jenis kelamin & Laki-laki & 8 & 18,2 \\
\multirow{4}{*}{ Pendidikan } & Perempuan & 36 & 81,8 \\
& SD & 11 & 25,0 \\
& SMP & 15 & 34,1 \\
Masa Kerja & SMA & 18 & 40,9 \\
& $<5$ thn & 35 & 87,5 \\
& $\geq 5$ thn & 9 & 16,5 \\
\hline
\end{tabular}

Berdasarkan tabel 1, diketahui umur responden sebagian besar $<40$ tahun yaitu $54,5 \%$. Jenis kelamin responden sebagian besar responden adalahperempuan yaitu $81,8 \%$. Pendidikan responden sebagian besar SMAyaitu 40,9\% dan masa kerja responden sebagian besar $<5$ tahun yaitu $79,5 \%$

Pada tabel 2 diketahui pengetahuan responden sebagian besar baik yaitu 52,3\%. Sikap responden sebagian besar positif yaitu $54,5 \%$. Omset bulanan, sebagian besar responden memiliki omset yang rendah sebanyak 25 orang $(56,8 \%)$. Sebagian besar tidak ada pengawasan internal yaitu 63,6 dan tidak ada pengawasan eksternalnya yaitu $61,4 \%$. Sehingga sebanyak $70,5 \%$ responden menyatakan kantin sekolah tidak laik.

Tabel 2. Distribusi Responden berdasarkan Variable yang Diteliti

\begin{tabular}{llcc}
\hline \multicolumn{1}{c}{ Variabel } & \multicolumn{1}{c}{ Kategori } & n & \% \\
\hline Pengetahuan & Baik & 23 & 52,3 \\
& Kurang Baik & 21 & 47,7 \\
Sikap & Positif & 24 & 54,5 \\
& Negatif & 20 & 45,5 \\
Omset & Tinggi & 19 & 43,2 \\
Bulanan & Rendah & 25 & 56,8 \\
Pengawasan & Ada & 16 & 36,4 \\
Internal & Tidak Ada & 28 & 63,6 \\
Pengawasan & Ada & 17 & 38,6 \\
Eksternal & Tidak Ada & 27 & 61,4 \\
Kelaikan & Laik & 13 & 29,5 \\
Kantin & Tidak Laik & 31 & 70,5 \\
\hline
\end{tabular}

Berdasarkan tabel 3diketahui bahwa dari $52,3 \%$ responden yang memliki pengetahuan baik, terdapat $25 \%$ kantin yang laik dan $27,3 \%$ yang tidak laik. Kemudian dari $47,7 \%$ responden yang memiliki pengetahuan kurang baik, terdapat $27,3 \%$ kantin yang laik dan 43,2\% yang tidak laik. Hasil uji statistik menunjukkan nilai $\mathrm{p}=0,014<0,050$, artinya ada hubungan yang signifikan antara pengetahuan pengelola kantin dengan kelaikan kantin sehat, dan nilai PR $=5,022$, artinya pengetahuan yang baik dari pengelola kantin akan meningkatkan kelaikan kantin sehat 5,022 kali lebih besar dibandingan dengan yang berpengetahuan yang kurang.

Berdasarkan sikap diketahui bahwa dari 54,5\% responden yang memiliki sikap positif, terdapat $27,2 \%$ kantin yang laik dan 27,3\%kantin tidak laik. Kemudian dari 45,5\%responden yang memiliki sikap negatif, terdapat $2,3 \%$ kantin yang laik dan $27,3 \%$ kantin tidak laik. Hasil uji statistik menunjukkan nilai $\mathrm{p}=0,003<0,050$, artinya ada hubungan yang signifikan antara sikap pengelola kantin dengan 
Tabel 3. Hubungan Pengetahuan, Sikap Pengelola Kantin, Omset Bulanan, Pengawasan Internal dan eksternal dengan Kelaikan Kantin Sehat

\begin{tabular}{|c|c|c|c|c|c|c|c|}
\hline \multirow{3}{*}{ Variabel } & \multirow{3}{*}{ Kategori } & \multicolumn{4}{|c|}{ Kelaikan Kantin } & \multirow{3}{*}{ Pv } & \multirow{3}{*}{ PR } \\
\hline & & \multicolumn{2}{|c|}{ Laik } & \multicolumn{2}{|c|}{ Tidak Laik } & & \\
\hline & & $\mathbf{n}$ & $\%$ & $\mathbf{n}$ & $\%$ & & \\
\hline \multirow[t]{2}{*}{ Pengetahuan } & Baik & 11 & 25,0 & 12 & 27,3 & \multirow{2}{*}{0,014} & \multirow{2}{*}{5,022} \\
\hline & Kurang Baik & 2 & 27,3 & 19 & 43,2 & & \\
\hline \multirow[t]{2}{*}{ Sikap } & Positif & 12 & 27,2 & 12 & 27,3 & \multirow{2}{*}{0,003} & \multirow{2}{*}{10,000} \\
\hline & Negatif & 1 & 2,3 & 19 & 43,2 & & \\
\hline \multirow[t]{2}{*}{ Omset Bulanan } & Tinggi & 10 & 22,7 & 9 & 20,5 & \multirow{2}{*}{0,010} & \multirow{2}{*}{4,386} \\
\hline & Rendah & 3 & 6,8 & 22 & 50,0 & & \\
\hline Pengawasan & Ada & 9 & 20,5 & 7 & 15,9 & \multirow{2}{*}{0,010} & \multirow{2}{*}{3,938} \\
\hline Internal & Tidak Ada & 4 & 9,1 & 24 & 54,5 & & \\
\hline Pengawasan & Ada & 10 & 22,7 & 7 & 15,9 & \multirow{2}{*}{0,002} & \multirow{2}{*}{5,294} \\
\hline Eksternal & Tidak Ada & 3 & 6,8 & 24 & 54,5 & & \\
\hline
\end{tabular}

kelaikan kantin sehat di Sekolah Dasar Kecamatan Medan Belawan, dan nilai PR $=10,000$, artinya pengelola kantin yang memiliki sikap yang positif akan meningkatkan 10 kali lebih besar kelaikan kantin sehat dibandingkan dengan pengelola kantin yangmemiliki sikap negatif.

Berdasarkan omset bulanandiketahui bahwa dari $43,2 \%$ responden yang omset bulanannya tinggi, terdapat $22,7 \%$ kantin yang laik dan 20,5\%yang tidak laik. Kemudian dari 56,8\%responden yangomset bulanannya rendah, terapat $6,8 \%$ kantin yang laik dan $50 \%$ kantin yang tidak laik. Hasil uji satatistik menunjukkan nilai $\mathrm{p}=0,010<0,050$, artinya ada hubungan yang signifikan antara omset bulanan kantin dengan kelaikan kantin sehat, dan nilai $P R=4,386$, artinya tingginya omset bulanan kantin akan meningkatkan kelaikan kantin sehat sebesar 4,386 kali lebih besar dibandingkan dengan omset yang rendah.

Berdasarkan pengawasan internal diketahui bahwa dari $36,4 \%$ yang ada pengawasan internal dari pihak sekolah, terdapat 20,5\% kantin yang laik dan $15,9 \%$ kantin yang tidak. Kemudian dari $63,6 \%$ yang tidak ada pengawasan internal dari pihak sekolah, terdapat $9,1 \%$ kantin yang laik dan $54,5 \%$ yang tidak laik. Hasil uji statistik menunjukkan nilai $\mathrm{p}=0,010<$ 0,050 , artinya ada hubungan yang signifikan antara pengawasan internal dengan kelaikan kantin sehat, dan nilai $\mathrm{PR}=3,938$, artinya adanya pengawasan internal dari pihak sekolah akan meningkatkan kelaikan kantin sehat sebesar 3,938 kali lebih besar dibandingkan dengan yang tidak ada pengawasan internalnya.

Berdasarkan pengawasan eksternal diketahui bahwa dari $38,6 \%$ yang ada pengawasan eksternal dari puskesmas, terdapat $22,7 \%$ kantin yang laik dan $15,9 \%$ yang tidak laik. Kemudian dari $61,4 \%$ yang tidak ada pengawasan eksternal dari pihak sekolah, terdapat6,8\%kantin yang laik dan $54,5 \%$ yang tidak laik. Hasil uji statistik menunjukkan nilai $\mathrm{p}=0,002<0,050$, artinya ada hubungan yang signifikan antara pengawasan eksternal dengan kelaikan kantin sehat, dan nilai $\mathrm{PR}=$ 5,294, artinya adanya pengawasan eksternal dari pihak sekolah akan meningkatkan kelaikan kantin sehat sebesar 5,294 kali lebih besar dibandingkan dengan yang tidak ada pengawasan eksternalnya.

Berdasarkan tabel 4 diatas menunjukkan bahwa setelah dilakukan uji regresi logistik berganda melalui metode enter dengan 1 langkah maka dapat diketahui bahwa variabel yang dominan berhubungan dengan kelaikan kantin sehat di Sekolah Dasar Kecamatan Medan Belawan adalah faktor pengetahuan 
Tabel 4. Hasil Akhir Uji Regresi Logistik Berganda

\begin{tabular}{|c|c|c|c|c|c|}
\hline \multirow{2}{*}{ Variabel } & \multirow{2}{*}{ B } & \multirow{2}{*}{ Sig } & \multirow{2}{*}{ Exp B } & \multicolumn{2}{|c|}{ 95\% CI } \\
\hline & & & & Lower & Upper \\
\hline $\begin{array}{l}\text { Pengetahuan Pengelola } \\
\text { Kantin }\end{array}$ & 3,095 & ,020 & 22,080 & 1,622 & 300,603 \\
\hline Sikap Pengelola Kantin & 3,097 & 053 & 22,127 & 966 & 506,970 \\
\hline Omset Bulanan Knatin & 2,131 &, 102 & 8,423 & 654 & 108,462 \\
\hline Pengawasan Internal & 277 &, 800 & 1,319 & ,155 & 11,201 \\
\hline Pengawasan Eksternal & 946 & ,445 & 2,575 & ,228 & 29,102 \\
\hline Constant & $-12,183$ & 004 &, 000 & & \\
\hline
\end{tabular}

pengelola kantin dengan nilai Exp. B sebesar 22,080.

Dengan demikian berarti pengetahuan pengelola kantin berhubungan secara signifikan terhadap kelaikan kantin sehat dengan nilai $\mathrm{p}=0,020$ dan nilai $\mathrm{OR}$ $(\operatorname{Exp} \mathrm{B})=22,080$ artinya bahwa pengetahuan yang baik dari pengelola kantin memiliki kecenderungan meningkatkan kelaikan kantin sehat sebesar22,080 kali lebih besar dibandingkan dengan pengetahuan pengelola kantin yang kurang.

\section{Pembahasan}

\section{Hubungan Pengetahuan Pengelola Kantin Dengan Kelaikan Kantin Sehat di Sekolah Dasar Kecamatan Medan Belawan}

Berdasarkan hasil distribusi frekuensi diketahui bahwa pengetahuan sebagian besar responden baik yaitu $52,3 \%$, dan hasil uji statistik menunjukkan adanya hubungan yang dignifikan antara pengelola kantin dengan kelaikan kantin sehat di Sekolah Dasar Kecamatan Medan Belawan $(\mathrm{p}=0,003<0,05)$, yang berarti bahwa tingkat pengetahuan pengelola kantin akan berhubungan dengan kelaikan kantin sehat di Sekolah Dasar Kecamatan Medan Belawan.

Sesuai dengan penelitian yang dilakukan di Sekolah Dasar Kecamatan Medan Belawan diperoleh bahwa pengelola kantin yang berpengetahuan baik terdapat $27,3 \%$ kantin yang tidak laik dan dari yang berpengetahuan kurang baik terdapat 43,2\% kantin yang tidak laik.

$\begin{array}{ccc}\text { Pengelola kantin } & \text { mempunyai } \\ \text { peranan penting dalam } & \text { pengolahan }\end{array}$

makanan yang sangat mempengaruhi keadaan higiene sanitasi, faktor sumber daya manusia diantaranya adalah pendidikan yang mengarah pada pengetahuan tentang kebersihan diri sendiri dan lingkungan. Sebagaimana diketahui bahwa sebagian besar pengelola kantin berpengetahuan baik yaitu 52,3\%. Dengan demikian berarti pengelola kantin sehat telah memiliki pengetahuan yang baik tentang keamanan pangan sehingga pengelola kantin mengetahui makanan atau jajanan yang baik untuk dijual di kantin sehat. Pengelola kantin juga telah mengerti cara pemasakan bahan makanan menurut gizi dan kesehatan, serta memelihara kebersihan alat-alat makan (mencuci air bersih yang mengalir dan sabun).

Dan berdasarkan data penelitian diketahui bahwa sebagian besar pengelola kantin berpendidikan SMA (40,9\%), yang berarti pengelola kantin pendidikan menengah. Tingkat pendidikan pengelola kantin akan mempengaruhi wawasan atau pengetahuannya, pengelola kantin yang berpendidikan lebih tinggi akan mempunyai pengetahuan yang lebih luas dibandingkan dengan seseorang yang tingkat pendidikannya lebih rendah. Pengelola kantin yang memiliki tingkat pendidikan yang rendah akan mempengaruhi pengetahuannya tentang higiene sanitasi pengolahan makanan yang dapat mempengaruhi kualitas makanan yang disajikan kepada konsumen.

Namun berdasarkan hasil temuan di lapangan diperoleh bahwa meskipun pengetahuan responden baik namun ketidaklaikan kantin sekolah lebih mendominasi. Hal ini disebabkan banyak 
pengelola kantin yang kurang memperhatikan fasilitas sanitasi, higine sanitasi, pengolahan bahan makanan, pengelolaan tempat penyimpanan, penyajian makanan, dan penggunaan peralatan pada kantin sekolah yang dikelolanya. Hal ini dapat dilihat dari tindakan pengelola kantin yang tidak memperhatikan kebersihan tempat pengolahan makanannya, tempat penyajian makanan yang tidak bersih dan makanan yang disajikan dalam keadaan terbuka (tidak ditutup), banyak sampah berserakan, juga terdapat lalat yang berterbangan sehingga dikhawatirkan lalat bisa singgah ke makanan yang disajikan. Kondisi tersebut tentunya mempengaruhi higiene sanitasi kantin sekolah tersebut.

Sehubungan dengan hal tersbut, maka pengelola kantin harus mendapatkan kursus atau pelatihan di bidang higiene dan sanitasi makanan baik yang diselenggarakan oleh pihak sekolah maupun instansi kesehatan terkait di wilayah Kecamatan Medan Belawan, agar pengelola kantin dapat mengelola kantinnya dengan baik sesuai dengan persyaratan higiene sanitasi kantin sehat di sekolah.

\section{Hubungan Sikap Pengelola Kantin Dengan Kelaikan Kantin Sehat di Sekolah Dasar Kecamatan Medan Belawan}

Berdasarkan dimana melalui data frekuensi diperoleh bahwa sikap sebagian besar responden positif yaitu $54,5 \%$ yang ditunjukkan dengan pernyataan positif dari responden yang merupakan pengelola kantin mengenai higiene sanitasi dalam pengelolaan kantin meliputi fasilitas sanitasi, pengolahan bahan makanan, pengelolaan tempat penyimpanan, penyajian makanan, dan penggunaan peralatan. Hasil statistik juga menunjukkan terdapat hubungan yang signifikan antara sikap pengelola kantin dengan kelaikan kantin sehat di Sekolah Dasar Kecamatan Medan Belawan $(\mathrm{p}=0,003<0,05)$.
Pengetahuan, berpikir, keyakinan dan emosi memegang peranan penting, ${ }^{4}$ dalam menentukan sikap dan faktor-faktor yang mempengaruhi sikap adalah pengalaman pribadi dimana apabila pengalaman tersebut meninggalkan kesan yang kuat, pengaruh orang lain yang dianggap penting, pengaruh kebudayaan, media massa, lembaga pendidikan, dan faktor emosional. Sehingga pengetahuan dan pengalaman diri dapat membentuk sikap seseorang. ${ }^{5}$

Berdasarkan hasil pengolahan data diperoleh bahwa dari 24 orang responden yang memiliki sikap positif, terdapat 12 orang yang memiliki kantin yang laik dan 12 orang tidak laik. Kemudian dari 20 orang yang memiliki sikap yang negatif, ada 1 orang yang memiliki kantik yang laik dan 19 orang kurang laik.

Sikap yang baik dari pengelola kantin dalam pengolahan makanan ditunjukkan dengan tidak merokok pada saat bekerja, selalu mencuci tangan selama bekerja, setelah bekerja, dan setelah keluar dari toilet, selalu memakai pakaian kerja yang benar dan bersih, menutup mulut saat batuk dan bersin dan tidak menyisir rambut di dekat makanan. Namun meskipun responden memberikan pernyataan positif mengenai higiene sanitasi dalam pengelolaan kantin meliputi fasilitas sanitasi, pengolahan bahan makanan, pengelolaan tempat penyimpanan, penyajian makanan, dan penggunaan peralatan. Namun kondisi di lapangan menunjukkan sebahagian besar kantin di Sekolah Dasar Kecamatan Medan Belawan tidak memenuhi kriteria kantin sehat. Hal ini disebabkan kurangnya perhatian dari pengelola kantin agar layak menjadi kantin yang sehat.

\section{Hubungan Omset Bulanan Kantin Dengan Kelaikan Kantin Sehat di Sekolah Dasar Kecamatan Medan Belawan}

Berdasarkan hasil distribusi frekuensi diperoleh bahwa responden memiliki omset bulanan rendah yaitu 
56,8\%. dan hasil uji statistik menunjukkan terdapat hubungan yang signifikan antara omset bulanana kantin edngan kelaikan kantin sehat di Sekolah Dasar Kecamatan Medan Belawan $(\mathrm{p}=0,010<0,05)$, yang berarti bahwa besarnya omset bulanan kantin akan mempengaruhi kelaikan kantin sehat.

Signifikansi hubungan antara omset bulanan kantin dengan kelaikan kantin sehat di Sekolah Dasar Medan Kota, dimana sebanyak 62,2\% responden mendapatkan omset harian rendah yaitu $\leq$ Rp. $200.000 .^{6}$

Dalam pengelolaan kantin, omset juga menentukan kemajuan pengelolaan kantin. Semakin tinggi omset suatu kantin sekolah, makin semakin tinggi juga laju pergerakan penjualan barang/jasa yang dijajakan di kantin, tetapi belum tentu berbanding lurus dengan kondisi penerapan higiene - sanitasi di dalam kantin. Karena jika kantin semakin ramai dikunjungi siswa-siswi bisa jadi, kondisi higiene-sanitasi semakin berkurang. ${ }^{4}$

Sehubungan dengan hal tersebut, data yang diperoleh menunjukkan bahwa besarnya omset bulanan kantin yang di Sekolah Dasar Kecamatan Medan Belawan sebagian besar rendah yang berkisar $\pm \mathrm{Rp}$. 100.000,- perharinya, dimana dari 25 orang yang menyatakan omset bulanannya rendah, ada 3 orang yang memiliki kantin yang laik dan 22 orang tidak laik. Dengan demikian berarti besarnya omset kantin yang diperoleh tidak memberikan dampak yang berati bagi kelaikan kantin sehat.

\section{Hubungan Pengawasan Internal Dengan Kelaikan Kantin Sehat di Sekolah Dasar Kecamatan Medan Belawan}

Berdasarkan hasil distribusi

frekuensi diperoleh bahwa sebagian besar responden tidak ada mendapatkan pengawasan internal dari pihak sekolah yaitu 63,6\%, dan hasil uji statistik menunjukkan terdapat signifikansi hubungan pengawasan internal dengan kelaikan kantin sehat di Sekolah Dasar Kecamatan Medan Belawan $(p=0,010<$
0,05). Hal ini menunjukkan bahwa pengawasan internal yang dilakukan oleh pihak sekolah akan menunjang terciptanya kelaikan kantin sehat.

Adanya hubungan pengawasan internal dengan kelaikan kantin sehat, dimana sebanyak $62,2 \%$ responden tidak pernah mendapatkan pengawasan internal dari pihak sekolah. ${ }^{6}$

Pengawasan internal merupakan pengawasan yang dilakukan oleh badan atau orang yang ada di lingkungan unit organisasi yang diperiksa. Hubungan antar aparat pengawasan dengan pihak yang diawasi adalah keduanya berada dalam satu unit organisasi yang sama. Dalam hal ini pihak sekolah sebagai pihak yang merupakan pihak internal, melakukan pengawasan terhadap pemilik kantin, apakah penyelenggaraan kantin senantiasa menerapkan higiene dan sanitasi yang baik. $^{6}$

Dalam penelitian yang dilaksanakan di kantin Sekolah Dasar Kecamatan Medan Belawan sehubungan dengan kelaikan sehat, maka pengawasan perlu dilakukan terhadap kualitas makanan, kebersihan, pengelola, peralatan, dan ruangan kantin agar tujuan penyediaan kantin sehat dapat tercapai. Adapun pengawasan ini ditugaskan pada guru piket. Namun kondisi di lapangan menunjukkan sebagian besar sekolah tidak melakukan pengawasan kepada kantin sekolah, sehingga tujuan kantin sehat tidak tercapai dengan optimal, karena dengan tidak adanya pengawasan mengakibatkan pihak sekolah maupun pengelola kantin kurang memperhatikan kualitas makanan, kebersihan kantin, peralatan kantin, dan ruangan kantin.

\section{Hubungan Pengawasan Eksternal Dengan Kelaikan Kantin Sehat di Sekolah Dasar Kecamatan Medan Belawan}

Berdasarkan hasil distribusi frekuensi diketahui bahwa sebagian besar responden tidak ada mendapatkan pengawasan eksternal $(641,4 \%)$. Hasil uji 
statistik menunjukkan terdapat signifikansi hubungan pengawasan eksternal dengan kelaikan kantin sehat di Sekolah Dasar Kecamatan Medan Belawan ( $\mathrm{p}=0,010<$ 0,05). Hal ini menunjukkan bahwa pengawasan eksternal yang dilakukan oleh instansi kesehatan akan menunjang terciptanya kelaikan kantin sehat.

Pengawasan eksternal merupakan pengawasan yang dilakukan oleh badan atau orang yang berasal dari unit organisasi lain selain unit organisasi yang diperiksa. Hubungan antar aparat pengawasan dengan pihak yang diawasi adalah ketuanya tidak berbeda dalam satu unit organisasi yang sama. Dalam hal ini, pengawasan eksternal dilakukan oleh instansi pemerintah terkait seperti Dinas Kesehatan, Badan POM RI, dll, untuk memastikan apakah pelaksanaan operasional kantin telah menerapkan higiene dan sanitasi yang baik. ${ }^{6}$

Sehubungan dengan penelitian yang dilaksanakan di kantin Sekolah Dasar Kecamatan Medan Belawan mengenai kelaikan sehat, maka pengawasan harus dilakukan oleh puskesmas Belawan dengan mengecek kualitas makanan, kebersihan kantin, pengelolan makanan, peralatan yang digunakan, dan kondisi ruangan kantin. Namun kondisi di lapangan menunjukkan sebagian besar puskesmas Belawan tidak ada melakukan pengawasan terhadap kantin-kantin Sekolah Dasar di Kecamatan Medan Belawan. Sehingga dengan tidak adanya pengawasan tersebut kondisi kantin kurang laik untuk dikatakan sehat, karena kuranya pengarahan serta petunjuk dari petugas kesehatan Puskesmas Belawan mengenai penyelenggaraan kantin sehat di sekolah.

\section{Faktor Dominan yang Berhubungan Dengan Kelaikan Kantin Sehat di Sekolah Dasar Kecamatan Medan Belawan}

Berdasarkan hasil uji statistik melalui regresi logistik berganda diketahui bahwa pengetahuan pengelola kantin berhubungan secara signifikan terhadap kelaikan kantin sehat dengan nilai $\mathrm{p}=0,020$ dan nilai $\mathrm{OR}$
$($ Exp B $)=22,080$ menunjukkan bahwa variabel pengetahuan merupakan faktor dominan yang berhubungan dengan kelaikan kantin sehat di Sekolah Dasar Kecamatan Medan Belawan, yang artinya bahwa pengetahuan yang baik dari pengelola kantin memiliki kecenderungan meningkatkan kelaikan kantin sehat sebesar 22,080 kali lebih besar dibandingkan dengan pengetahuan pengelola kantin yang kurang.

Tingkat pengetahuan yangbaik yang dimiliki pengelola kantin tentunya akan berdampak pada kelaikan kantin yang dikelolanya, karena pengelola kantin yang memiliki pengetahuan yang baik tentunya akan memahami dengan baik higiene sanitasi yang baik pada kantin sehat sesuai dengan syarat yang dikeluarkan oleh Kemenkes sehingga kelaikan kantin akan terpenuhi dengan baik bila pengelola kantin memiliki pengetahuan yang baik pula.

Oleh karena itu dalam upaya untuk mendukung peningkatan pengetahuan dari pengelola kantin maka perlu diberikan pelatihan di bidang higiene sanitasi makanan, baik yang diselenggarakan oleh pihak sekolah maupun instansi kesehatan terkait di wilayah Kecamatan Medan Belawan. Hal ini perlu dilakukan agar pengelola kantin tidak hanya sekedar tahu mengenai higiene sanitasi makanan namun juga melakukan tindakan yang baik pula dengan lebih memperhatikan fasilitas sanitasi, higine sanitasi, pengolahan bahan makanan, pengelolaan tempat penyimpanan, penyajian makanan, dan penggunaan peralatan pada kantin sekolah yang dikelolanya. Sehingga program kantin sehat dapat terwujud sesuai dengan tujuannya.

\section{Kesimpulan}

Dari hasil penelitian dapat disimpulkan bahwa sebagian besar kantin di SD Kecamatan Medan Belawan masih dalam keadaan tidak laik. Ketidaklaikan kantin ini berhubungan dengan faktor pengetahuan pengelola kantin, sikap 
pengelola kantin, omset bulanan kantin, pengawasan internal dan pengawasan eksternal. Adapun faktor pengetahuan pengelola kantin merupakan faktor dominan yang mempengaruhi kelaikan kantin sehat.

\section{Saran}

Bagi Pengelola Kantin Hendaknya memperhatikan kondisi fasilitas sanitasi, higine sanitasi, pengolahan bahan makanan, pengelolaan tempat penyimpanan, penyajian makanan, dan penggunaan peralatan pada kantin sekolah yang dikelolanya agar kantin yang dikelolanya memnuhi standar dalam kantin sehat dalam Kemnekes serta untuk menjaga kualitas makan yang dijual di kantin tersebut. Bagi pihak sekolah hendaknya melakukan pengawasan terhadap kualitas makanan, kebersihan, pengelola, peralatan, dan ruangan kantin secara berkesinambungan agar tujuan pencapaian kelaikan kantin sehat tercapai dengan baik. Bagi puskesmas belawan agar melakukan pengawasan yang rutin ke kantin-kantin Sekolah Dasar dengan melakukan pengecekan terhadap kualitas makanan, kebersihan, pengelola, peralatan, dan ruangan kantin serta melakukan penyuluhan ke pihak sekolah mengenai kelaikan kantin sehat sesuai dengan persyaratan sanitasi kantin Kemenkes.

\section{Daftar Pustaka}

1. FAO. Milk and diary products in human nutrition Roma: Food and Agriculture Organization of the United Nations. 2013. p. 4351.

2. Badan POM RI. Peraturan Kepala Badan Pengawasan Obat dan Makanan Republik Indonesia No. HK. 03.1.23.08.11.07331 Tahun 2011 tentang Metode Analisis Kosmetika. Jakarta :BPOM; 2011.

3. World Health Organisation. Maternal Mortaily; 2003.

4. Notoatmodjo, Ilmu Perilaku Kesehatan. Jakarta: Rineka Cipta; 2014

5. Azwar. Metode Penelitian. Yogyakarta: Pustaka Pelajar; 2013.

6. Siagian. Manajemen Sumber Daya Manusia. Jakarta: Bumi Aksara; 2015. 